\title{
What's the Harm? Why the Mainstreaming of Complementary and Alternative Medicine is an Ethical Problem
}

Lawrence Torcello

Department of Philosophy, Rochester Institute of Technology

\begin{abstract}
This paper argues that it is morally irresponsible for modern medical providers or health care institutions to support and advocate the integration of CAM practices (i.e. homeopathy, acupuncture, energy healing, etc.) with conventional modern medicine. The results of such practices are not reliable beyond that of placebo. As a corollary, it is argued that prescribing placebos perceived to stand outside the norm of modern medicine is morally inappropriate. Even when such treatments do no direct physical harm, they create unnecessary barriers to patients' informed understanding of their health.
\end{abstract}

KEY WORDS: Acupuncture; CAM; Clifford; Ethics; Homeopathy; Integrative Medicine; Moral Hazard; Placebo

\section{INTRODUCTION}

People from a variety of backgrounds regularly visit acupuncturists, homeopaths, naturopaths, and other practitioners of alternatives to science-based medical care. Such "complementary and alternative medicine" (CAM), as the name suggests, is understood to be a complement to or replacement for science-based medicine. Increasingly, people seek alternative medical treatments with the tacit approval or outright recommendation of mainstream health care practitioners. According to one 2009 survey, United States citizens spend approximately 3.9 billion dollars on CAM annually. ${ }^{1}$ In keeping with the widespread and growing use of CAM, the United States has a governmental agency called the National Center for Complementary and Alternative Medicine (NCCAM), which is an arm of the National Institute of Health (NIH). NCCAM was founded in 1991, replacing the Office of Alternative Medicine (OAM). According to their website: 
The mission of NCCAM is to define, through rigorous scientific investigation, the usefulness and safety of complementary and alternative medicine interventions and their roles in improving health and health care. ${ }^{2}$

The problem with this statement is closely related to the key problem with CAM itself: the statement promises to define the usefulness and safety of CAM, rather than establishing whether CAM has any scientific merit in the first place. ${ }^{i}$ I want to look closely at NCCAM's mission statement, here at the outset, because it is paradigmatic of the way CAM is presented publically and therefore of the way it is understood. Rather than speak on behalf of CAM advocates, I want first to allow them to speak for themselves. Once they do, however, I believe I can show that CAM's goals, like the goals of NCCAM, encourage irresponsible clinical recommendations and contribute to the spread of dangerous misinformation among patients and the general public. NCCAM aims to "integrate" CAM practices into modern medicine and to do so "scientifically." I will argue that when mainstream health care providers and institutions allow or recommend this integration, their complicity represents a serious ethical breach of responsible health care practice and education.

Back for a moment to the NCCAM mission statement referenced above. Is the essential goal of evaluating whether CAM actually has any scientific merit implicit to NCCAM's mission, such that I might have first interpreted it uncharitably? Not if the rest of the website is to be believed. It continues:

NCCAM's programs and organization incorporate 3 long-range goals:

1.Advance the science and practice of symptom management.

2.Develop effective, practical, personalized strategies for promoting health and well-being. 3.Enable better evidence-based decision making regarding CAM use and its integration into health care and health promotion.

\footnotetext{
${ }^{\mathrm{i}}$ In my discussion of CAM I am limiting myself to practices that are often used as replacements for mainstream medical care (E.g. Acupuncture, Homeopathy, Naturopathy, etc.) I am not referring to things like music therapy, physical therapy, and art therapy.
} 
The first two goals have nothing in particular to do with CAM. Intentionally or not, goals (1) and (2) are benign sounding cognitive primers that make the controversial circularity of the third goal less apparent. The wording of (3) suggests that NCCAM's raison d'être is the integration of CAM practices into mainstream medicine and not the scientific evaluation of such practices.

Yet here we can already identify the difficulty CAM presents, because if any serious evidence for a CAM treatment is presented, it no longer is useful or appropriate to refer to the treatment as "CAM" at all. In other words, the reason there are no scientifically based complementary and alternative approaches to mainstream medicine is that effective medical approaches become part of standard medical care. The constant research, vetting of research, and implementation of research in standard medical science is focused on utilizing therapies that work, and that work best among possible alternatives, which is to say in a transparently evidential and testable way.

Yet the fact that such a position must be asserted and is regularly met with disbelief, fear, and cynicism regarding the scientific authority of standard medicine also points to an element of incoherency in NCCAM's approach. NCCAM and its supporters aim to integrate CAM into mainstream medicine (per goal 3). In this aim, the advocates of integration assume that there is or can be a meaningful way to integrate CAM treatments into science-based practices (on the authority of "rigorous scientific investigation"). At the same time, advocates of such integration believe that CAM can remain separate from mainstream science-based practices, and they usually imply that a strength of CAM is its independence from the difficulties that face mainstream medicine (whether economic interests that threaten to oversell certain forms of 
treatment or a conservatism in practice that threatens to deny access to certain forms of treatment).

NCCAM and other advocates of the integration of CAM into standard medicine make a fundamental error, then, in understanding the nature of standard medical science. Again, a "scientific approach to CAM" is literally a contradiction in terms, because insofar as science establishes the efficacy of any so-called CAM practice, it is no longer "complimentary" or "alternative"; it becomes part of standard care. This is how medical science, like all science works, through the examination of evidence.

In order to make the case that mainstream health care providers and institutions should not promote the integration of CAM as part of modern medical practice, and that doing so is ethically irresponsible, I will call upon the concept of "moral hazard." Part II of this article sets a theoretical foundation upon the concept of moral hazard by drawing on W.K. Clifford's Ethics of Belief and by articulating the ethical and epistemological issues entailed there. In Part III, I will explain the grounds on which the promotion of CAM practices among health care practitioners and institutions should be understood as professionally irresponsible and morally culpable. In Part IV, I will address some objections I anticipate from defenders of CAM. In the concluding Part V, I will offer a set of recommendations for integrating humanistic values into medical education - which is, I believe, what most people really hope to find when they settle for the traditional narratives of CAM practices.

\section{ETHICS OF BELIEF}

In his Ethics of Belief (1877), mathematician and philosopher W.K. Clifford sets out a framework meant to guide the formation of ethically warranted beliefs as contrasted with ethically blameworthy beliefs. Clifford offers two illustrations of ethically blameworthy beliefs 
(i.e. insufficiently supported beliefs). ${ }^{\text {ii }}$ The first and more famous example begins with the story of a ship owner who rents an unsafe vessel to passengers setting course for the new world. In the example given by Clifford, it is made known that the owner has reason to believe that this particular ship is unsafe. Nevertheless, for the sake of financial profit and convenience, the ship owner talks himself out of any doubts he may have and trusts in "providence" for the ship's safe voyage. The ship is wrecked in stormy seas. All aboard perish and the owner quietly collects the insurance money due to him.

The second example involves practitioners of a reform sect of Christianity who are rumored to indoctrinate children into practices the larger community considers to be of a particularly heretical nature. In the example, a committee is convened to investigate the allegations but fails to do so in a meaningful way, thus essentially condemning the religious sect to widespread persecution on the basis of unsubstantiated rumors. Eventually the false nature of the allegations is revealed. Consequently, the community comes to view the investigative committee as irresponsible and derelict in the performance of their commissioned duties.

In both of these examples, the locus of moral blameworthiness is easy to identify. To complicate things Clifford revises his examples and asks if moral blameworthiness is obviated by different outcomes (e.g. the ship makes its way safely across the Atlantic; the religious reformists are not persecuted but rather tolerated by the citizens around them). Clifford concludes that outcomes are irrelevant. A lack of epistemic warrant independent of outcome determines the moral significance of these cases. Clifford reasons from these cases to the

\footnotetext{
ii I am discussing Clifford's approach in "The Ethics of Belief" for the purposes of this essay. Nevertheless, the idea that our epistemological practices are of ethical importance dates as far back as Socrates and can be found in the dialogues of Plato, the Meditations of Descartes, and the treatise' of John Locke to name just a few canonical figures from the history of philosophy.
} 
conclusion that "it is wrong, always, everywhere, and for anyone to believe anything on insufficient evidence."

Clifford bases his maxim on the following premises: (1) Beliefs that we accept set cognitive patterns for similar beliefs to take hold. (2) Beliefs that we accept will eventually exert an influence directly or indirectly on those we come in contact with in the larger community. There is a strong case to be made for both of these assertions. It can be argued that a large part of standard educational practice is predicated on the first statement being true, and it is a basic pedagogical assumption of logic and critical thinking that good cognitive habits are worth developing in order to avoid fallacious cognitive patterns. If a person accepts a fallacious form of reasoning in one situation, it is likely that she or he will apply the same pattern of reasoning to other situations.

One's willingness to accept a lack of evidence disproving claim " $\mathrm{X}$ " as supporting evidence for claim " $\mathrm{X}$ " is part of the cognitive pattern of reasoning known as argumentum ad ignorantiam, or an argument from ignorance. For example, I might say that no one has convincingly disproved that the lights I've seen in the desert sky are alien spacecraft, therefore, they are alien spacecraft. And if I accept such reasoning in one case it is likely that I will accept such reasoning in similar cases. For instance, if I am prone to accept that an unknown light in the sky is an extraterrestrial spacecraft because I cannot disprove such a guess, then I am more likely to accept claims that extraterrestrial technology is being hidden by the U.S. Government simply because I cannot disprove that claim. Similarly, if one is prone to accept post hoc reasoning (i.e. that correlation entails causation) in one situation, then one is more likely to do so in other situations. For example, we might picture a couple who have experienced "unexplained 
infertility" successfully conceiving after undergoing acupuncture treatments for fertility, and then fallaciously crediting acupuncture with their successful pregnancy based solely on an anecdotal correlation. We might further picture that if this couple's child later shows signs of autism shortly after receiving vaccinations, the couple may similarly and fallaciously infer a causal link based on correlation. Yet scientific evidence supporting any causal link is lacking in both cases. Indeed, Clifford's first premise - that beliefs arrived at through fallacious cognitive patterns are likely to support the formation of additional beliefs predicated on such patterns - is consistent with recent findings in cognitive science with regard to patterns of conspiratorial thinking. ${ }^{4}$

A strong case can be made also for Clifford's second premise - that our accepted beliefs eventually exert an influence on our communities - and I would argue that it is even more pressing now than it was in Clifford's $19^{\text {th }}$ century. The rise of modern social media allows people to connect, share ideas, and forge relationships in ways that were nearly impossible to imagine at the time of Clifford's writing. Clifford's argument is that our beliefs, attitudes, and behaviors impact those around us in ways that we cannot easily foresee. Clifford maintains that our beliefs eventually will spill forth into our actions, or influence the actions of others, in ways that are largely out of our control. Clifford insists that it matters not whether a person vows to keep beliefs private, because our beliefs will influence our behaviors in ways beyond our awareness. And the fact is, whether we choose to defend Clifford's insights or not, we tacitly assume their truth whenever we set out to develop sound pedagogy and research standards in logic and science (e.g. the value of the double blinded study). If we reflect upon our experience at all, it is difficult to deny the fact that our beliefs have and do influence us and others even when we do not intend for them to do so. 
Based on this chain of probable influence, it is not difficult to make the case that we have epistemological and moral responsibilities when it comes to the development of our belief systems. Does it follow then, as Clifford argues, that it is always wrong, everywhere, and for everyone, to believe something without sufficient evidence? One obvious criticism (though perhaps not as devastating as it might first seem) is that Clifford's principle is subject to his own standard of warranted belief. In other words, one might counter Clifford by arguing that there is not sufficient evidence for his ethical principle, and thus that Clifford is guilty of his own charge.

However, Clifford does not merely state his principle; he provides an argument that grants sufficient reason for its acceptance. In fact, Clifford does go on to describe the sort of beliefs he deems warranted. They are beliefs supported by our experience and vetted through critical examination. Such standards of warranted belief are consistent with those we accept in modern scientific and academic inquiry. Beliefs backed by scientific evidence, well-reasoned inference, and open scrutiny are justified beliefs. Beliefs that lack such backing are unjustified and, according to Clifford, morally irresponsible. ${ }^{\text {iii }}$

I maintain that there is good reason to accept the moral implications if belief formation, though it is not necessary to follow Clifford in the entirety of his categorical condemnation. One problem with Clifford's categorical claim is that some beliefs fall outside the category of beliefs subject to verification. ${ }^{\text {iv }}$ Matters of aesthetic preference are not open to the sort of scrutiny that Clifford's moral epistemology requires. Can one seriously make the claim that settling one's belief on whether Bach or Beethoven is the superior composer is of moral importance? This

\footnotetext{
iii I have made a similar argument with regard to the politically motivated denial of anthropogenic global warming. See Torcello (2011).

${ }^{\text {iv }}$ I am not claiming that Clifford is a verificationist. It simply is the case that certain beliefs are not easily justified and remain a matter of taste and opinion. Such beliefs are unavoidable if one is to live a life that goes beyond the academic text.
} 
question can only be answered reasonably in the negative. Furthermore, even if we take Clifford's own examples utterly seriously as templates, we are still left not knowing whether it is the belief that is immoral, or the failure to act with due diligence, independent of belief, that is morally problematic.

Let us go back to Clifford's first example of the ship owner. If the ship owner erroneously believed that the vessel was seaworthy, but nevertheless had the ship inspected as a standard safety precaution, is it still reasonable to say that his belief in the ship's seaworthiness is immoral? It seems to make more sense to say the owner's failure to act responsibly, regardless of belief, led to a tragic loss of life. Clifford might counter that it is the belief in the ship's safety that spills over into the owner's actions, or in this case inaction, and thus creates the moral culpability. Clifford is right to assert that our beliefs are likely to spill over into our actions. But I do not hold the view that we are powerless to guard against such a tendency. The methodological project of modern science, aware of the dangers of subjective preconceptions, is aimed at guarding researchers from their own confirmation bias. Saying that holding an unwarranted belief makes someone immoral is awkwardly close to a doctrine of "thought crime." How then should Clifford's insights most reasonably be applied?

\section{Moral Hazard}

The concept of moral hazard is widely used in economics to characterize a situation in which the acting agent is insulated from risks placed on others through her actions. A modest conclusion to draw from Clifford's ethics of belief is that our beliefs carry a moral hazard. This means that our beliefs have the potential to spill over into our actions, or to influence the actions of others, in a way that places them at risk of undue harms. If our beliefs, given their moral 
hazard, lead to harmful actions or omissions, then we are morally culpable for the consequences. This application of moral hazard condemns the ship owner's failure to guarantee the seaworthiness of his vessel as a matter of procedure, regardless of belief. It is the lack of due diligence, and not the privately held belief, that is immoral, but it is the unwarranted belief that creates the occasion for such morally fraught neglect. I submit that the moral hazard of belief is amplified in this case since the ship's owner is positioned to assert influence over both the safety and the beliefs of his passengers in ways unavailable to others.

To accept this adapted version of the ethics of belief is to endorse the view that the formation of our beliefs involves a burden of moral responsibility. Consequently, while we cannot escape the moral responsibility we bear for our unjustified beliefs, we do not necessarily carry moral culpability for them. It is important to recognize the difference between moral hazard (responsibility) and moral guilt. The former is ubiquitous in a way that the latter is not. Moral hazard results from the constant responsibility we have regarding the epistemic quality of our beliefs. It is the particular acts or omissions based on our morally hazardous beliefs that are potentially morally blameworthy.

\section{SCIENCE, PROFESSIONAL INFLUENCE, AND ETHICAL RESPONSIBILITY}

I have argued elsewhere that the moral hazard associated with our beliefs is enough to support and recommend an accompanying ethics of public inquiry that extends to all citizens insofar as they are bound together as a political body. ${ }^{5}$ Consistent with that claim I have argued that the denial of established scientific consensus is best described as "pseudoskeptical," and that 
pseudoskeptical claims asserted in the public sphere are morally condemnable. ${ }^{\mathrm{v}}$ Such claims are morally condemnable within the framework of moral hazard I have outlined above. This is especially the case when scientific consensus is relevant to public policy (e.g. the scientific consensus on anthropogenic global warming). In particular, pseudoskeptical claims are blameworthy when asserted in the public sphere by those with greater influence than the average citizen. As an example, if someone with access to the public sphere, such as a politically influential public figure, believes that standard vaccinations pose a serious health risk, this belief should be categorized as a morally hazardous pseudoskeptical belief. If the public figure defends this view in the public domain, without acknowledging the contrary scientific consensus, then such speech is morally blameworthy and ought to be strongly condemned as unethical. ${ }^{\mathrm{vi}}$ This is because the ill-informed and unwarranted opinion of the public figure on this matter is of greater than normal public influence. A moral onus is on public officials to speak responsibly on matters relevant to public policy. Furthermore, given the ample availability of accurate information in the public sphere, and the increased access that politicians have to experts, there is no excuse for being ignorant of established scientific consensus. The same can be said of any other public figure with greater access to information and an above average public profile (i.e. journalists, celebrities, academics) ${ }^{6}$

\footnotetext{
${ }^{\mathrm{v}}$ The process of science involves the application of methodological skepticism. Indeed the one characteristic that all scientific fields share is the use of rigorous skepticism in an attempt to disprove a favored hypothesis and guard against confirmation bias. Because of this a conclusion that has become part of established scientific consensus is grounded in the inherently skeptical process of scientific inquiry. When such claims are called into doubt without recognizing the scientific consensus it is more a function of ideology, or cynicism, than skepticism. Therefore, it is appropriate to call such doubts (examples of science denialism) pseudoskeptical.

vi Examples of politically affiliated public figures who have behaved immorally with regard to the public dissemination of medical misinformation (according to my argument) are Michelle Bachmann and Robert Kennedy. In a 2011 Republican Primary debate, and afterword, Representative Michelle Bachmann made unfounded allegations regarding alleged dangers of the HPV Vaccine. See Denise Grady (2011) and see Phil Plait (accessed 2013).
} 
A similar situation applies to health care professionals or institutions that recommend CAM treatments to patients and the public. Such treatments are scientifically unsubstantiated, or at best highly controversial. Indeed, public figures who make pseudoskeptical claims, if confronted, are sometimes forced to qualify their statements by admitting they are not actual physicians or scientists. ${ }^{7}$ This occurrence calls attention to the fact that actual scientists and physicians hold a high level of credibility in the eyes of the public. The recommendation of scientifically unsubstantiated procedures is a serious lapse of professional ethics among healthcare providers by virtue of their reasonably presumed medical expertise.

Regarding unsubstantiated medical procedures the default position of the healthcare practitioner ought to be that they are clinically unwarranted. ${ }^{\text {vii }}$ A null hypothesis is assumed in science that places the burden of proof on those promoting a novel treatment to provide sufficient evidence of the treatment's effectiveness. If such evidence is not available, inclusion in the clinical scheme of modern medicine is unwarranted. When mainstream health care practitioners or medical institutions endorse CAM treatments it violates the reasonable expectation that one will not be subjected to, or recommended, treatments unsupported by medical science. The endorsement may be as mild as a physician pointing out that some patients have reported "positive results from acupuncture." Even if the physician does not believe that such a practice will be effective, she may reason that such practices are unlikely to harm a person and may even have a placebo benefit. ${ }^{8}$ However, insofar as this suggestion misleads a patient into thinking that there is scientific merit to CAM practices, it interferes with the patient's ability to make informed decisions regarding their health care. ${ }^{9}$ It may also, consistent with the

vii One exception to this rule is under circumstances of research when a patient consents, within the bounds of informed consent, to undergo an experimental treatment. This is not an exception that can be applied to most instances of CAMs integration into mainstream healthcare practices 
Cliffordian argument made above, spill over into other aspects of the patient's life—including an influence on others.

Given the preceding arguments it is reasonable to treat our beliefs as holding a moral hazard insofar as they have the potential to influence others in disastrous ways. When consulting with their patients physicians have a greater than normal responsibility due to their position of authority and influence on a patient's health care beliefs. Therefore, treating physicians ought to observe and act according to the following argument.

1. CAM Treatments are (at best) scientifically controversial

2. The recommendation of a scientifically controversial treatment is normally unwarranted.

3. Unwarranted medical advice is morally hazardous.

4. A morally hazardous recommendation, on the part of a health care practitioner, ought to have a strong reasonable justification.

5. The weak nature of evidence in support of CAM renders strong reasonable justifications impossible.

Conclusion: It is inappropriate, and morally condemnable, to recommend CAM practices to patients.

As I have stated above, CAM treatments are at best controversial; it may be just as well to call them unwarranted. One of the mistakes that both laypeople and physicians may make is thinking that a CAM practice must be disproven before it can be disregarded. This is not the case for two reasons: (1) A burden of evidence falls upon CAM practitioners to justify their claims, and not on the scientific community to refute their claims. (2) One cannot prove a negative; for this reason waiting for any treatment to be conclusively disproven before it is abandoned can only be predicated on a fallacious appeal to ignorance. Overlooking this reality may lead some medical practitioners and CAM practitioners alike to assume that more research is needed. It is not practical however, or necessary, to continue to research claims that have a long track record of failing to produce conclusive evidence. It is enough to recognize that CAM is controversial in 
order to justify its dismissal as a recommendation to patients, and the lack of evidence for CAM suggests that it is more strongly condemnable as unwarranted.

It bears saying that it is morally irresponsible to give dubious medical advice to a patient. As such, it is never appropriate for a health care practitioner, or medical institution, to recommend or tacitly endorse CAM practices to patients. ${ }^{\text {vii }}$ Indeed, it is a morally blameworthy breach of trust when providers and institutions overtly or implicitly recommend controversial practices to unsuspecting patients and to the general public. ${ }^{10}$

\section{POSSIBLE OBJECTIONS}

\section{A. CAM is Scientifically Justifiable}

An obvious objection is that CAM, or at least some forms of CAM, are scientifically defendable. This claim is made in error. It may be the case that a small minority of individual studies can be found that seem to support the use of a particular CAM treatment. However, a closer examination of these studies will almost always suggest that there is no greater benefit than one could expect from a placebo. Additionally, most such studies are found in journals that overtly endorse the integration of CAM into mainstream health practices. Not all "peer-review" is equally unbiased or equally blinded. But even if we can uncover in mainstream journals a few studies that report the marginal effectiveness of a CAM beyond placebo published, the scientific

\footnotetext{
viii Johns Hopkins provides a good example of an offending institution. On the website for Johns Hopkins Center for Integrative Medicine one can read descriptions of treatments remarkably out of step with the modern medical science, with which one reasonably presumes their medical students are otherwise exposed. For example, a sample passage describing the acupuncture services available at the center reads: "Acupuncture is an ancient form of Chinese medicine dating back over 5,000 years. It is based on the concept that the body has specific channels (meridians) through which energy (chi) flows. While this energy, or chi, is flowing smoothly, there will be no specific pain or disease, but if the chi is either deficient or excess in quantity, or is not flowing freely, there will be disease. When acupuncture needles are placed in specific points on the skin, energy is redirected to bring about a healing response." See Johns Hopkins, Integrative Medicine and Digestive Center, Acupuncture.
} 
reality is that a significant number of replication studies are necessary to draw any lasting scientific conclusions, and here CAM inevitably nosedives. Without successful replication studies, a smattering of positive CAM results look like no more than a quirk of flawed analysis or methodology. Because again, if a CAM practice does start to look effective in repeated testing, then it becomes warranted scientifically just as it stops being a CAM practice-instead of CAM, it becomes a straightforwardly science-based medical practice. ${ }^{\text {ix }}$

\section{B. CAM Justified as Placebo}

Some claim that CAM is warranted as a placebo. The idea is that CAM practices are unlikely to do any harm, even if they only work as placebos. Debates about the placebo effect and whether it is ethical for health care practitioners to use the placebo effect on their patients goes beyond the scope of this paper. However, even if we assume that the use of placebo can in some cases be justified, it does not follow that every type of placebo is justified. This paper has argued that CAM practices are harmful in that they contribute to patient confusion regarding the nature of medicine and practice of maintaining or assessing health. Belief in the effectiveness of CAM practices can undermine patient compliance with science based conventional therapies. Recommendations from a physician tend to carry authority, so the recommendation of CAM, even as a placebo, is potentially more harmful than helpful to a patient. If placebos are to be used, then their use ought to be restricted to placebos that are not perceived as outside of modern medicine. Such a precaution minimizes the risk of misinformation with regard to a patient's health and the nature of modern medicine. The limited effects a placebo may bring

\footnotetext{
${ }^{\text {ix }}$ One might retort that the vast majority of studies published in medical journals never get replicated. This may be true and may even point to a separate problem regarding the sort of things that are emphasized in modern medical research and scientific publication. This problem is beyond the scope of the current paper. Nevertheless, the issue is irrelevant as to whether or not there actually is in current existence a meaningful body of evidence to support the integration of various CAM practices into modern medical practice.
} 
about are insignificant against the long term harms that inaccurate medical information and the resulting embrace of ineffective treatments may cause patients. For this reason it is worth emphasizing: if placebos are to be used at all they must not be placebos that lead to patient misinformation regarding the nature of modern medicine.

\section{The Argument Presented is Overly Paternalistic}

It might be claimed that the abolitionist position argued for in this paper is overly paternalistic and undermines patient autonomy. This charge does not follow. Patients are free to seek out whatever alternative forms of treatment they wish, but my argument is that they should not be doing so with the impression that it is sanctioned by their health care provider or mainstream health care institutions. Furthermore, insofar as CAM practices mislead patients with or without the presumed consent of a conventional health care provider or institution, they undermine patient autonomy. This is because true patient autonomy requires capacity and competence with regard to informed consent. Medical misinformation serves to undermine competent decision making and therefore is not reasonably conducive to patient autonomy. The importance of informed consent cannot be overemphasized as an important concept in medical ethics. One might plausibly assert that one goal of health care treatment in general is to restore a patient to as much functional autonomy consistent with a reasonable quality of life as can be achieved. Clear and reliable health care information and a realistic understanding of one's condition are essential to these goals. To the degree that advocacy of CAM creates misinformation among patients it undermines patient autonomy.

\section{CONCLUDING RECOMMENDATIONS}


It is morally irresponsible for modern medical providers or health care institutions to support and advocate the integration of CAM practices with conventional modern medicine. When asked about CAM practices such as homeopathy, acupuncture, energy healing, naturopathy, etc., health care providers should be clear with their patients about the lack of supporting scientific evidence for CAM practices, and about what such a lack of evidence means (i.e., that it doesn't necessarily mean testing hasn't occurred at all). Such practices are inappropriate as elaborate placebos for reasons already stated. It bears repeating: placebos should not be used if they are perceived by patients to somehow stand outside the norm of modern medicine. Health care practitioners have no good reason for complicity.

One of the things that plausibly attract patients to CAM practitioners is the emphasis such practitioners traditionally place on personal care and interaction with clients. A given CAM treatment may involve a significant amount of time spent in soothing empathic conversation, soft music, pleasant scents, physical touch, and encouragement. Given the lack of evidence for CAM, it stands to reason that the personal attention and time that CAM practitioners give to their clients is the key trigger for any placebo effects experienced.

Happily, human empathy and a good patient-physician relationship are not dependent on CAM practices. Care of the whole individual and recognition of a patient's humanity is perfectly compatible with the goals of modern medicine. The value of humanistic patient care is often lauded by modern medical institutions and practitioners. Unfortunately it does not always go beyond rhetorical endorsements. Providing CAM exposure to medical students is no substitute for a program of medical humanities that integrates philosophical ethics, literature, art, history, 
and the social sciences into medical education. ${ }^{\mathrm{x}}$ In order to actually foster the sort of psychological and emotional benefits that many patients desire in their health care experience, medical institutions should more robustly support the integration of humanities in health care education and practice. Such efforts can help to correct deficiencies in a modern medical system that often provides little time for personalized interaction between healthcare practitioners and their patients. Doing so will be far more beneficial to medical practitioners, medical education, and patients than the currently misguided integration of CAM into modern medical practice.

\footnotetext{
${ }^{\mathrm{x}}$ Many institutions do support programs in the medical humanities and they should be commended for doing so. Unfortunately some of these same schools also support CAM integration. It should be clear from this article that CAM integration deserves no support as part of the legitimate integration of the humanities in health care.
} 


\footnotetext{
${ }^{1}$ Nahin, RL, Barnes PM, Stussman BJ, and Bloom B. "Costs of Complementary and Alternative Medicine (CAM) and Frequency of Visits to CAM Practitioners: United States," 2007 [360KB PDF]. National health statistics reports; no 18. Hyattsville, MD: National Center for Health Statistics. 2009.

2 National Center for Complementary and Alternative Medicine. NCCAM Facts-at-a-Glance and Mission. http://nccam.nih.gov/about/ataglance (accessed 11 June

2013).

${ }^{3}$ Clifford W.K., The Ethics of Belief and Other Essays, ed. Timothy Madigan, (1999) Prometheus Books pp.74-77.

${ }^{4}$ Lewandowsky Stephan, Oberauer Klaus, Gignac Gilles, (2013) NASA faked the moon landing-Therefore (climate) Science is a Hoax: An Anatomy of the Motivated Rejection of Science. Psychological Science. 24(5): 622633

${ }^{5}$ Torcello L. "The Ethics of Inquiry, Scientific Belief, and Public Discourse," Public Affairs Quarterly 2011; 25(3): 197-215

${ }^{6}$ Phil Plait, "Robert F. Kennedy Jr.: Anti-Vaxxer," Slate, June 5 2013,

${ }^{7}$ Denise Grady, "Remark on HPV Vaccine Could Ripple for Years," New York Times, September 19, 2011, http://www.nytimes.com/2011/09/20/health/20hpv.html?pagewanted=all\&_r=0 (Accessed 10/10/2013)

8 Palle Rosted MD, The Medical Acupuncture Web Page. "Adverse Reactions after Acupuncture," http://medvetacupuncture.org/english/articles/adverse1.html (accessed 10/16/2013).

${ }^{9}$ Junhua Ahang, Hongcai Shang, Xiumei Gao, Edzard Ernst, "Acupuncture-related adverse events: a systematic review of the Chinese literature." Bulletin of the World Health Organization, (http://www.who.int/bulletin/volumes/88/12/10-076737/en/) (accessed 10/16/2013).

${ }_{10}$ Johns Hopkins, Integrative Medicine and Digestive Center, Acupuncture http://www.hopkinsmedicine.org/integrative_medicine_digestive_center/services/acupuncture.html (accessed
} 10/16/2013) 